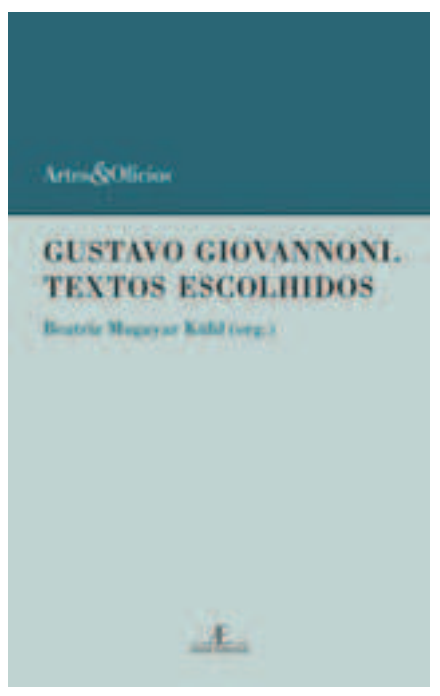

Gustano Gionannoni. TeXtos escolhidos.

Beatriz Mugayar Kühl (Org.), Ateliê

Editorial, ANo: 2013

ISBN: $978-85-7480-60$ I-3

Mirandulina Maria Moreira Azevedo

pós-

\title{
DA ARTE DO ENCONTRO DO NOVO E DO ANTIGO: A FILOLOGIA EM ARQUITETURA, DE GIOVANNONI
}

A Artes\&Ofícios, coleção da Ateliê Editorial sobre obras de restauração, história da arte e seu universo, teve seu número nove dedicado a Gustavo Giovannoni (1873-1947). Resultado de um esforço coletivo, a obra sinaliza o predomínio do assunto restauro na coleção, e a continuidade do trabalho da organizadora, Beatriz Kühl. Centrada na tradução de obras significativas, inclui conceitos e palavras-chave de autores fundamentais para a disciplina da preservação, perfazendo um roteiro de referência para formação e debate.

A retomada de Giovannoni nos últimos anos, depois de um período de questionamentos por parte de autores como Bruno Zevi, Renato Boneli, Roberto Pane e Giulio Carlo Argan, está relacionada ao contexto de discussões contemporâneas sobre patrimônio urbano, conceito cujo amadurecimento foi fortemente influenciado por suas reflexões. No livro $A$ alegoria do patrimônio, F. Choay afirma que é necessário restituir-lhe o lugar que merece, no campo da História. A recuperação recente de seu legado deve-se aos esforços reiterados de Guido Zucconi, C. Varagnoli, Gaetano Miarelli Mariani e Andrea Pane, entre outros. O volume em questão contém a tradução de reflexões importantes do autor, precedidas por apresentações de cinco autores, de instituições diversas: Andrea Pane (Università degli Studi di Napoli Federico II), com "Atualidade de Gustavo Giovannoni", apresenta o quadro da atuação profissional da época e o papel singular desempenhado pelo engenheiro, a herança de Camilo Boito e a consolidação da via intermediária, da qual se fez intérprete; Renata Campelo Cabral e Carlos Roberto M. de Andrade (IAU-USP), responsáveis a quatro mãos pelas notas de apresentação e tradução do texto "Vecchia Città ed Edilizia Nuova" (1913), espécie de "portal" para a introdução à problemática giovannoniana; por 
fim, Manoela Rufinoni (Unifesp) apresenta "Gustavo Giovannoni e o Restauro Urbano", reavaliando, para o presente, a contribuição do autor. Beatriz Kühl (FAUUSP) traduziu quatro dos textos escolhido - o primeiro de Pane, já citado, e três pertencentes a Giovannoni: "II 'Diradamento' Edilizio dei Vecchio Centri. II Quartiere dela Renascença em Roma" (1913), "La Restauration des Monuments en Italie" (1933) e "Restauro dei Monumenti" (1936).

As contribuições da pequena coletânea apresentam uma visão formada por um consenso, em que se enfatiza a alta produtividade e amplitude de interesses de Giovannoni, de que se destacam três pontos: Urbanismo, restauro e história da Arquitetura. Pane, citando Guido Zucconi, considera tal síntese próxima do que hoje se denomina "conservação de bens arquitetônicos e ambientais". Em parte, a visada de Zucconi, de evitar fragmentar os três níveis, sustenta a interpretação do conjunto dos autores.

A época justificava perfeitamente o papel assumido pelo engenheiro, que soube responder à altura ao complexo quadro das relações entre política e técnica da modernização vigente. O campo de conhecimento da Engenharia, no início do século 20, foi desenvolvido com a perspectiva de atender às demandas das transformações territoriais e técnicas, em curso desde o século anterior, a exigir uma nova ordem, pautada por controle e planejamento. O problema seria depois vivido pela maioria das grandes cidades. No caso de Roma, o aspecto antigo, monumental, já secularmente, era promotor da própria identidade urbana e tornava-se, assim, condicionante de qualquer operação de modernização; em outras palavras, naquela cidade, o valor do passado deveria ser levado em consideração, como parte essencial do problema. A figura histórica a responder à peculiar situação italiana seria Gustavo Giovannoni. Não por acaso, Engenharia sua formação, 1895 - e Saneamento - sua primeira especialização, 1896 forneceriam os instrumentos para diagnóstico e tratamento do problema da cidade, tanto do adensamento de seu núcleo, quanto de seu crescimento para além de seus contornos; usaria o termo "drenagem" para se referir à ação necessária para restringir a circulação nas áreas centrais. Entendia que seria preciso reservar o crescimento para as áreas de expansão, de maneira a preservar as construções mais antigas, cujo conhecimento buscou, em sua segunda especialização, em História da Arte (1897-1899), junto a Adolfo Venturi.

O texto "Vecchia Città ed Edilizia Nuova", "Velhas Cidades e Nova Construção Urbana", na tradução de Renata Cabral e Carlos Roberto de Andrade, pode ser visto como a síntese de um "insight metodológico", pois reúne a compreensão precisa da transformação histórica das cidades (da qual os engenheiros eram agentes) e suas consequências na destruição do artefato urbano tradicional, com a consciência da necessidade de preservá-lo. O foco do autor, Roma, objeto por excelência da arte urbana, e que, como tal, também expressava uma cultura urbana cujos contornos são eminentemente italianos.

Atento a uma nova cultura urbanística, na qual se destacavam países como Alemanha e Inglaterra, Giovanoni dialogava com autores de diversas origens: Sobem, Goecke, Henrici, Ojetti, Fierens-Gevaert, Charles Buls, e Rubbiani, entre outros. Deste modo, o engenheiro-historiador pôde formular uma aproximação entre as novas teorias urbanísticas e uma teoria de restauro. Da leitura, em nova chave, do clássico "A construção da cidade segundo seus princípios artísticos", de Camillo Sitte, mais que um diagnóstico sombrio sobre o futuro da cidade 
moderna, retiraria um conjunto de regras e códigos a serem aplicados em áreas que haviam perdido sua condição original. De Rubbiani, apreciaria o pitoresco e os critérios projetuais da varietà, onde "tudo é beleza num contínuo predomínio de curvas, de dobras, de ângulos". Desta dinâmica, em que a parte deve contribuir para o conjunto, entenderia que cada fragmento é significativo; em nota do texto sobre o bairro do Renascimento, explicava: como "tesselas de um magnífico mosaico".

A abordagem em restauro assumia novos contornos, pelo viés de um novo Urbanismo, cujas soluções formais seriam capazes de manter fisionomia de bairro e de cidade nas criações novas. Ao preferir a curva à reta, porque a primeira desvia, evita, preserva, e a segunda "desventra", definia-se um modus operandi para ampliar, "drenar" núcleos antigos e preservar monumentos e jardins. Em definitivo, estavam compreendidas as premissas de como abordar e dotar, as velhas estruturas, de condições de salubridade, de solidez e de funcionalidade, mantendo, ao mesmo tempo, o melhor do caráter do passado.

O passo seguinte seria tratar, na escala do edifício, do difícil encontro do novo com o antigo e, para isso, se valeria de sua condição de engenheiro, pois a solução se daria como resposta técnica, no campo dos procedimentos operacionais. Resolveria a questão com a intervenção exemplar no bairro do Renascimento; não realizaria muito outras do gênero, mas ficaria o texto "O 'Desbastamento' de Construções nos Velhos Centros. O Bairro do Renascimento em Roma" (1913). Giovannoni faria uma analogia com um procedimento técnico do cultivo de espécies vegetais, o diradamento, prática que inclui seleção e eliminação, com o intento de melhoria, traduzido como "desbastamento", por Beatriz Kühl, como também, antes, por Luciano Machado, na referida obra de F. Choay. Para Varagnoli, uma prefiguração desta estratégia pode ser vista em Roma, no projeto de ligação da Ponte Umberto com a Piazza Barberini, em 1902.

A transferência desta noção para o artefato urbano revela uma postura própria da engenharia, em uma situação que, de regra, critérios estilísticos ainda dominavam; seria a ciência, a partir desta ótica, a autorizar decisões que seriam difíceis, tanto no âmbito artístico quanto no político. O "desbastamento", em Giovannoni é, porém, muito mais que uma analogia simples, para justificar demolições necessárias. Trata-se de procedimento técnico de ordem filológica, aplicado à Arquitetura para ajuste da leitura urbana, em contextos de difícil legibilidade; ainda que seja negativo, isto é, que elimine formas, é também de ordem compositiva, já que o apagamento de determinados trechos é feito pelo bem da compreensão do conjunto. Como ele, também A. Riegl (1858-1905), ao confrontar o problema do restauro de pinturas parietais, oferecia soluções do mesmo teor filológico.

A ressalva que pode ser feita ao autor é que, ainda que conhecedor de História da Arquitetura, com nuances de refinamento, seu recorte do ambiente urbano sacrificava, em certa medida, a individualidade da obra arquitetônica, pela leitura predominantemente tipológica. Os representantes do chamado restauro crítico souberam apontar essas limitações com bastante argúcia: esta abordagem, exercida sem o necessário aprofundamento, poderia induzir a uma preservação conformista, limitada à manutenção de fachadas, e descurar de aspectos estruturais e espaciais importantes. Não é este o caso. O que se pode dizer é que Giovannoni, pela apropriada aplicação do "desbastamento" ao bairro 
do Renascimento, promoveu "a arte do encontro do novo com o antigo". Até então, essa relação se fazia no sentido de viabilizar as necessidades do novo, em detrimento dos valores consubstanciados no antigo; pela filologia giovannoniana, ao contrário, o desbastamento permite ao antigo expor sua harmonia. A natureza desta medida guarda alguma afinidade com as reflexões de Heidegger, em $A$ origem da obra de arte: o desbastamento seria um gesto de desvelo para com a obra do passado, que permitiria seu desvelamento.

As experiências e reflexões de Giovannoni foram decisivas para o amadurecimento da abordagem e do tratamento a serem dados aos monumentos, e apontava para a necessidade de definições mais articuladas na defesa dos patrimônios. Sua inserção na sociedade civil era de longa data, esteve presente em diversas associações de interesse coletivo e assumiria papel chave na criação da primeira Escola Superior de Arquitetura, em 1920, em Roma. Certamente, sua projeção como professor - ofício que tem como intenção instruir, o que requer saber influenciar - deve ter sido bastante potencializada, em razão de seu perfil de ativo participante da vida pública, e vice-versa, já que a ação pública se beneficiaria de sua fluência didática.

Atribui-se, com frequência, a diminuição do interesse pela figura de Gustavo Giovannoni a vários motivos: a inaplicabilidade dos métodos de restauro aos contextos de extensiva destruição do ambiente urbano do pós-guerra; no que tange à história da Arquitetura, suas dificuldades de compreensão em relação à Arquitetura moderna; ou, ainda, sua compatibilidade com a programação cultural fascista. Para F. Choay, "durante muito tempo se escamoteou a importância de Giovannonni em razão de paixões políticas e ideológicas".

A reavaliação de sua obra possui importância estratégica, para fazer frente às abordagens dominantes na cena contemporânea: a renovação predatória de áreas e as recorrentes práticas repristinatórias, dois extremos problemáticos enfrentados, no que diz respeito à preservação do patrimônio arquitetônico. No primeiro caso, agem as forças do mercado, por natureza, amnésicas; no segundo caso, agem aqueles que desejam preservar e consideram que isso seja possível, sem o atendimento aos princípios fundamentais do restauro.

A seleção de textos é, em si, uma resposta a essa situação, pois foi buscar em Giovannoni, em sua abordagem em duas escalas, referida por Pane, os argumentos de combate. Em primeiro lugar, a urbanística, alternativa à renovação urbana indiscriminada, com a fundamental reflexão sobre a preservação da parte antiga das cidades, e a relação desta com o conjunto da cidade mais novo e dinâmico, como demonstraram Renata Cabral e Carlos Roberto de Andrade e Manoela Rufinoni; em segundo lugar, a intervenção pontual, por meio da operação de desbastamento como procedimento indicado para a relação entre novo e antigo, bem como a recusa das repristinações, a distinguibilidade e a mínima intervenção, como princípios válidos para o restauro, enfatizados por Beatriz Kühl, nos últimos textos traduzidos: "O 'desbastamento' de Construções nos Velhos Centros. O Bairro do Renascimento em Roma" (1913), "A Restauração dos Monumentos na Itália" (1933) e "Verbete: Restauro dos Monumentos" (1936).

Conclui-se que a operação de revisão histórica que começou há certo tempo valorizou a contribuição de Giovannoni. Tal como a curva, que ele tanto estimava, a releitura de sua obra soube preservar o que há de boa herança para o presente. Ainda assim, o volume apreciado não pode contemplar, do mesmo modo, outros 
aspectos importantes da história da preservação, como sua filiação à interpretação filológica do restauro, elucidada por Carbonara no "Avvicinamento al restauro" (1997), ou ainda a reflexão do próprio Giovannoni sobre as experiências acumuladas, como base para o processo de formação do chamado restauro científico, exposta em "Questione di Architettura nella storia e nella vita" (1925): à classificação dos tipos de restauro (hoje, tão pouco apreciada), correspondiam procedimentos nascidos da práxis conservativa, que era então a mais respeitosa e sensível abordagem dos monumentos da época. Para o presente, C. Varagnoli, em "Gustavo Giovannoni riflessioni sul restauro agli inizi del XXI secolo" (2005), considera a leitura filológica da intervenção e a visão complexa do autor quanto ao objeto arquitetônico um guia para o restauro capaz de conservar e interpretar o passado.

Por fim, o desafio desta empreitada em torno de Giovannoni é tanto maior, na medida em que a seleção de textos parece falar diretamente "ao coração" dos problemas de hoje, pois, considerando a incipiente tradição da cultura preservacionista local, e sendo o autor, homem de "procedimentos", é possível que, em sua recepção, seja atribuído a estes uma importância maior do que a devida. Dito de outro modo: há risco de que o "procedimento" se descole da abordagem teórica que o ancorava e Ihe proporcionava sentido.

Trata-se, contudo, de textos escolhidos por uma autora que sabe que está num campo de batalha cultural, contexto em que o esforço coletivo realizado vem se somar, para mais uma bem acertada contribuição.

\section{Mirandulina Maria Moreira Azevedo}

Graduou-se em Arquitetura e Urbanismo pela Universidade Federal do Ceará (UFC), realizou mestrado e doutorado pela Universidade de São Paulo (USP), com auxílio de bolsas de estudo da Capes e do CNPq. Adquiriu experiência na área de Preservação de Patrimônio Cultural como pesquisadora e coordenadora do Projeto de Diretrizes e Recuperação do Patrimônio Habitacional em Madeira da Vila Ferroviária de Paranapiacaba, vinculado ao edital de Políticas Públicas da Fundação de Amparo à Pesquisa do Estado de São Paulo (Fapesp), no período 2003-2006, e desenvolvida na Fundação Santo André. Desde 1998, atua como professora na área de Teoria e História da Arquitetura e, nos últimos quatro anos, como Professor Associado I, tem sido responsável pelas disciplinas de Teoria da Arquitetura e Urbanismo, Arquitetura Brasileira e Técnicas Retrospectivas, na Universidade Metodista de Piracicaba (Unimep).

Universidade Metodista de Piracicaba, Faculdade de Engenharia e Arquitetura Rod. Santa Bárbara/Iracemápolis, km 1, Iracemápolis

13450-000 - Santa Bárbara d'Oeste, SP, Brasil

(19) $3455-2311$

mira.m.azevedo@gmail.com 